\title{
Maternal and Foetal Outcome in Cases of Placenta Previa, Accreta and Increta
}

\author{
Fauzia Anjum, ${ }^{1}$ Rabia Bashir, ${ }^{2}$ Arooba Rahim ${ }^{3}$
}

\begin{abstract}
Objective: To evaluate the maternal and foetal outcome in cases of placenta previa, placenta accrete and placenta increta.

Methods: Medical records of patients from $1 \mathrm{Feb}$ 2014 to 28 Feb 2015 were checked and patients who underwent caesarean section with a diagnosis of placenta previa types III and IV (and placenta accreta, increta and percreta) were identified. Their medical record files were retrieved and data collected regarding patients age, parity, previous LSCS, D\&C, blood loss, bladder injury, hysterectomy and use of B-lynch technique were recorded. Neonatal statistics were also recorded regarding birth weight, gender, APGAR score and need for admission in NICU.

Results: In total 37 cases of major placenta previa were identified. These included 8 cases with placenta accrete including 2 cases of placenta increta. No maternal death occurred amongst the studied cases. Only
\end{abstract}

\footnotetext{
${ }^{1}$ Assistant Professor of Obstetrics \& Gynaecology

Rashid Latif Medical College, and Consultant Hameed Lateef Hospital, Lahore

${ }^{2} 4^{\text {th }}$ Year Trainee, Hameed Lateef Hospital, Lahore

${ }^{3}$ Senior Registrar, Rashid Latif Medical College, Lahore
}

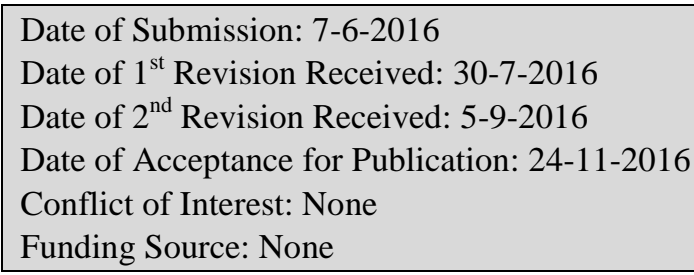

\section{Contribution}

All Authors have contributed in Study Design, Data Collection, Data Analysis, Data Interpretation, Manuscript Writing and Approval. one case of IUFD was identified. The incidence of placenta previa (major) was 29.95/1000 births. Average parity of patients with placenta accreta (PA) was significantly higher than cases of placenta previa (PP) $(2.75$ vs. $1.55, p=0.04)$. Similarly average number of LSCS in cases of PA was significantly higher than cases of PP (2.25 vs. $0.86, p=0.02)$. PA cases were delivered at a significantly earlier gestational age as compared to cases with PP (34.5 weeks vs. 37 weeks, $\mathrm{p}=0.01)$. Hysterectomy was done in $6(75 \%)$ cases of PA but in none with PP. Bladder injury occurred in $2(25 \%)$ cases of PA but in none with PP. Blood loss was also significantly higher in PA cases than PP cases $(3975 \mathrm{ml}$ vs. $1196 \mathrm{ml}, \mathrm{p}=0.006$ ).

Conclusion: At tertiary care hospitals, maternal and foetal outcomes for placenta previa and placenta accreta have improved owing to improved surgical techniques and better understanding of these conditions.

Keywords: Placenta previa, Placenta accrete, Postpartum hemorrhage.

\section{Introduction}

Placentaprevia (PP) is the presence of placental tissue which extends over or lies very close to the internal cervical os. Prevalence of placenta previa has been reported in the range of 3.5 to 4.6 per 1000 births. $^{1}$ Prevalence of PP is rising as a result of increasing rates of LSCS. ${ }^{2}$ New research on abnormal placentation suggests individualised approach to improve delivery timing. ${ }^{3}$ Risk factors for PP include previous PP, previous LSCS, multiple gestation, multiparity, advanced maternal age, previous abortion, previous intrauterine surgical procedure, male foetus and non-white race. Placenta previa has historically been associated with severe complications like ante partum, intra-partum and postpartum haemorrhages, which often nece- 
ssitate blood transfusion and/or hysterectomy. Maternal morbidity and mortality in cases of PP has been reported to be high in resource-poor countries. ${ }^{4}$

Placenta accreta (PA) is the implantation of placenta where anchoring placental villi attach to myometrium rather than decidua. In placenta increta the villi penetrate the myometrium and in placenta percreta they penetrate through myometrium to the serosa. PA and other forms of morbidly attached placenta are mostly found in association with PP. In this article the term placenta previa refers to PP without morbid placental attachment whereas PA is used for placenta attached to or penetrating the myometrium.

It has been reported that neonatal outcomes associated with PP have improved due to improved obstetric management, and better neonatal care. We hypothesised that foetal and maternal outcomes in cases of placenta previa, accreta and increta have improved due to advancements in obstetric care in the present times. Objective of our study was to test if this hypothesis was correct. We retrospectively studied cases of PP and PA who presented at Hameed Latif Hospital during the period from Feb 2014 to Feb 2015 and report the findings here.

\section{Patients and Methods}

It was a retrospective study which was carried out in Hameed Latif Hospital, Lahore Pakistan. Hameed Latif Hospital is a 250 bedded private sector tertiary care hospital and is a centre of excellence for gynaecology and obstetrics in the region. After obtaining approval from the hospital ethical committee, hospital records from 1 Feb 2014 to 28 Feb 2015 were checked. All patients who underwent caesarean section due to PP or PA were included in the study. Their medical record files were retrieved and data were collected regarding date of presentation, stage of pregnancy, obstetric history, type of placenta previa, emergency or elective caesarean section and amount of blood loss during the surgery. Blood loss had been calculated from the number of gauze pads soaked with blood during the surgery. Note was also made if any bladder injury had occurred during the surgery and if B-lynch technique was used to stop bleeding and save uterus. Data pertaining to baby including gender, birth weight, APGAR score at 1 and $5 \mathrm{~min}$ and need for admission to NICU were also recorded. Data were then analysed using MS Excel 2010. $P$ value $\leq 0.05$ was taken as statistically significant at $95 \%$ confidence interval.

\section{Results}

Total 37 patients were enrolled in the study. Placenta previa type III was diagnosed in $16(43.3 \%)$ patients and type IV in $21(56.7 \%)$ patients. Eight (21.6\%) patients (all with previa type IV) had placenta accreta including two with placenta increta. Total number of patients delivered during the study period was 1235 which gives us the incidence of placenta previa major as 29.95/1000 births. Mean age of the patients was $31.37(24-42)$ years, mean age for previa (PP) patients without accreta was $31.17(\mathrm{SD} \pm 4.36)$ years and mean age for PA was 32.12 ( $\mathrm{SD} \pm 4.05)$ years. Women with PA had higher average parity than those with PP $(2.75$ vs. 1.55$)(p=0.04)$. Eighty seven percent patients with PA had had one or more LSCS and mean number of LSCS that these patients had was 2.25. This is in contrast with corresponding figures for PP without PA where $48 \%$ patients had had LSCS before. Average number of LSCS in patients with PP without PA was 0.86 . When mean number of LSCS between PP and PA were compared, the difference was found statistically significant $(\mathrm{p}=0.02)$. Mean gestational age at the time of LSCS was significantly less in PA as compared to PP (34.5 vs. 37 weeks $p=0.01)$. Caesarean hysterectomy was performed in 6 cases of PA but in none of the cases with PP without PA ( $p=0.001)$. Bladder injury was noted in 2 patients with PA but in none with PP without PA ( $p=0.08)$. B-lynch technique was used in 2 cases of placenta accreta to stop haemorrhage and hysterectomy was successfully avoided in both these patients. B-lynch was used in 2 cases of PP without accreta and hysterectomy was avoided in these two as well. Hysterectomy was performed in both cases of placenta increta. Hysterectomy was also performed in both cases of PA in which bladder injury occurred.

Two (25\%) patients with PA underwent LSCS before 32 weeks gestation while Four (50\%) had LSCS between 33 and 37 weeks gestation and another 2 (25\%) reached term before LSCS. Most (22, 75.8\%) patients with PP had LSCS at or after 37 weeks gestation while 7 (24.2\%) were delivered between 33 and 37 weeks. None of the patients with PP delivered before 32 weeks gestation.

Thirty nine foetuses were delivered (there were two twin pregnancies). There was one intra-uterine foetal demise (IUFD). Ratio of female to male foetus in PP was 18:13 (1:0.72) while in PA it was 3:5 (1:1.66). Seven $(24.13 \%)$ of 29 women with PP had LSCS before term (37 Weeks). Average birth weight 
Table 1: Comparison of placenta previa cases with and without accreta.

\begin{tabular}{|l|l|c|c|c|}
\hline \multicolumn{1}{|c|}{ Variable } & Total & $\begin{array}{c}\text { Placenta Previa } \\
\text { without Accreta }\end{array}$ & $\begin{array}{c}\text { Placenta Previa } \\
\text { with Accreta }\end{array}$ & p-value \\
\hline Age (years) (mean \pm SD) & 31.37 & $31.17(4.36)$ & $32.12(4.05)$ & 0.28 \\
\hline Parity(mean \pm SD) & & $1.55(1.63)$ & $2.75(1.66)$ & 0.04 \\
\hline $\begin{array}{l}\text { Previous LSCS } \\
\text { Patients (n, \%) }\end{array}$ & & $14(48.27 \%)$ & $7(87.5 \%)$ & 0.02 \\
Mean number of LSCS ( \pm SD) & & $0.86(1.04)$ & $2.25(1.66)$ & \\
\hline Grade of PP & & 16 & 0 & \\
$\quad$ Type III & & $37(1.08)$ & $34.5(2.32)$ & 0.01 \\
$\quad$ Type IV & & 0 & $6(75 \%)$ & 0.001 \\
\hline Gestational age at delivery(weeks, (mean \pm SD) & & 0 & $2(25 \%)$ & 0.08 \\
\hline Caesarean hysterectomy (n, \%) & & $1196(607.38)$ & $3975(1924.8)$ & 0.006 \\
\hline Bladder injury (n, \%) & & $2(6.89 \%)$ & $2(25 \%)$ & \\
\hline Blood loss (ml) (mean \pm SD) & $4(10.8 \%)$ & & & \\
\hline B-Lynch & & & & \\
\hline
\end{tabular}

Table 2: Neonatal outcome in cases of placenta previa with and without accrete.

\begin{tabular}{|l|c|c|c|}
\hline \multicolumn{1}{|c|}{ Variable } & Placenta Previa without Accreta & Placenta Previa with Accreta & p-value \\
\hline $\begin{array}{l}\text { Gestational age (mean } \pm \text { SD) } \\
>37 \text { wks }\end{array}$ & $37(1.08)$ & $34.5(2.32)$ & \\
\hline$<32$ weeks & 0 & 2 & \\
\hline $33-37$ weeks & $7(24.13 \%)$ & 2 & 0.09 \\
\hline$>37$ weeks & $22(75.86 \%)$ & $2.41(0.56)$ & 0.43 \\
\hline Birth weight $($ mean \pm SD) & $2.81(0.72)$ & $8.5(1.32)$ & \\
\hline APGAR(mean \pm SD) & 8.34 & 0 & \\
\hline IUD & 2 & 5 & \\
\hline Gender & 13 & 3 & \\
Male & 18 & $6 / 8$ & \\
\hline Female & $12 / 30$ & $0 / 8$ & \\
\hline Admission to NICU & $1 / 29$ & & \\
\hline
\end{tabular}

in cases of placenta previa was $2.81( \pm 0.72)$ which was insignificantly higher than cases with placenta accreta $(2.41 \pm 0.56), \mathrm{p}=0.09$. Similarly mean APGAR score for PP was $8.34( \pm 2.38)$ and that for PA was $8.5( \pm$ 1.32). This difference however was again not statistically significant $(\mathrm{p}=0.43)$. There was only one case of IUFD in PP cases whereas no case of IUFD was encountered in cases of PA. Forty (40\%) (12 of 30 live births) neonates in PP cases were admitted to neonatal ICU (NI-CU) while $75 \%$ of neonates in cases of PA had to be admitted to NICU.

\section{Discussion}

In present study preterm LSCS (before 37 weeks) was done in $24.13 \%$ of women with PP which is higher 
than overall average of preterm deliveries $(11 \%$ to $18 \%) .5$ No caesarean hysterectomy was performed for 29 cases of PP. This is in sharp contrast with some of the previously reported figures for hysterectomy rates in PP. ${ }^{6}$ It is perhaps a result of early diagnosis and cautious management of PP during pregnancy and LSCS. In a study by Dola et $\mathrm{al}^{7}$ published in 2003 , the authors reported around $20 \%$ caesarean hysterectomy for PP type IV. Over the past 2 decades obstetricians seem to have improved significantly in terms of carrying the pregnancy as close to term as possible in order to achieve foetal maturity.

Figures for preterm caesarean delivery were also surprisingly low in our study. About one fourth $(24.13 \%)$ of total patients underwent LSCS before 37 weeks which is in contrast to the figures reported in past. Mcshane et $\mathrm{al}^{8}$ in their study published in 1985 reported that $66.6 \%$ of cases with PP were delivered before 36 weeks gestation despite best available management at that time.

Average blood loss in cases of major placenta previa has been reported in the range of $1500-1600$ ml. ${ }^{9,10}$ Average blood loss in present study $(1196 \mathrm{ml})$ is lower than these earlier studies again reflecting an improvement in maternal outcomes.

Thirty nine babies were delivered in total (two were twin pregnancies). There was only one IUFD and it was an anomalous baby. This is a significantly better neonatal outcome as old studies reported much worse outcomes for neonates with peri-natal mortality reaching as high as $37 \% .{ }^{11}$ A study carried out at Sheikh Zayed post graduate institute Lahore in 2004 to 2007 reported neonatal mortality rate of $14 \%$ for placenta previa patients. ${ }^{12}$ Peri-natal mortality in PP cases has been variously reported from $2.3 \%{ }^{13}$ to $50 \% .^{14}$ In the same study maternal mortality was $2 \%$. In another study carried out at civil Hospital Karachi, published in 2010 reported $23.38 \%$ early neonatal mortality in cases of placentaprevia. ${ }^{15}$ Other complications associated with PP including respiratory distress syndrome, major congenital anomalies were not seen in present study.

An alternative approach for management of PA by conservative method was suggested and tested in a multicenter French study by Sentilhes et al. ${ }^{16}$ Placenta was left in situ in expectation that spontaneous resorption of placenta would follow naturally. This treatment approach was successful in $78 \%$ patients whereas $21.6 \%$ patients had either primary or delayed hysterectomy. A study by Read et al reported a caesarean hysterectomy rate of $63.63 \%$ for cases with PA. ${ }^{17}$ This approach was also recommended based on a large descriptive study in UK reported by Fitzpatrick et al. The study concluded that women who have no attempt to remove their placenta for conserving uterus have reduced levels of haemorrhage and reduced need for blood transfusion. ${ }^{18}$

\section{Conclusion}

Present study suggests that in tertiary care centres in Pakistan, maternal and foetal outcomes for pregnancies with major placenta previa (type III and IV) are not as poor as previously reported but morbidity is significantly increased if placenta previa is also complicated by placenta accerta or increta.

\section{References}

1. Faiz AS, Ananth CV. Etiology and risk factors for placenta previa: an overview and meta-analysis of observational studies. J Matern Fetal Neonatal Med. 2003; 13: 175.

2. Serena W, Masha K, Judith UH. Abnormal placentation: Twenty-year analysis. American Journal of Obstetrics and Gynecology. May, 2005; 192: 1458-61.

3. Vahanian SA, Vintzileos AM. Placental implantation abnormalities: a modern approach. CurrOpinObstet Gynecol. 2016; Epub ahead of print.

4. Olive EC, Roberts CL, Algert CS, Morris JM. Placenta previa maternal morbidity and place of birth. Aust N Z J Obstet Gynaecol. 2005; 45: 219.

5. WHO, March of Dimes, Partnership for Maternal, Newborn and Child Health, Save the Children. Born too soon: the global action report on preterm birth www.who.int/maternal_child_adolescent/documents/bo rn_too_soon/en/.

6. Humayun S, Nahid F. Comparison of pregnancy outcome among placenta previa and abruption. Ann king Edward med uni Jan - Mar, 2015; 11: 58-9.

7. Dola CP, Garite TJ, Dowling DD, Friend D, Ahdoot D, Asrat T. Placenta previa: does its type affect pregnancy outcome? American Journal of Perinatology, 2003; 20 (7): 353-360.

8. Mcshane, Patricia M. Heyl, Peter S. Epstein, Michael F. Maternal and Perinatal Morbidity Resulting From Placenta Previa. Obstetrics \& Gynecology. Feb. 1985.

9. Oya A, Nakai A, Miyake H, Kawabata I, Takeshita T. Risk facors for peripartum blood transfusion in women with placenatprevia: a retrospective analysis. J Nippon Med Sc. 2008; 75: 146-151.

10. Hong JY, Jee YS, Yoon, Kim SM. Comparison of general and epidural anesthesia in eective cesarean section for placenta previatotalis: maternal hemodynamics, blood loss and neonatal outcome. Intl J Obstet Anesth. Jan. 2003; 12: 12-6. 
11. Crenshaw, Carlylejr, Jones, dE, Darnell Parker, Roy T. Placenta previa: a survey of twenty years experience with improved perinatal survival by expectant therapy and cesarean delivery. Obstetrical \& gynaecological survey. Jul, 1973.

12. Saeed Z, Mikram, Tazian S, Saeed M, Saeed R. Placenta previa. Professional Med J, Jan - Mar, 2009; 16: 139-44.

13. Crane, Joan MG, Hof VD, Michiel C, Dodds L, Armson B, et al. Neonatal outcomes with placenta previa. Obstetrics \& Gynecology, Apr. 1999; 93: 541-4.

14. Berhan Y. Predictors of Perinatal Mortality Associated with Placenta Previa and Placental Abruption: An Experience from a Low Income Country. Journal of Pregnancy, 2014; (2014): Article ID 307043, 10. Pages.
15. Raheel R, Tabassum R, Bhutto A, Riaz H, Hanif R. Fetal outcome in cases of placenta previa - a retrospective study. Med channel. Apr - Jun, 2010; 16: 256-9.

16. Sentilhes L, Ambroselli C, Kayem G, Provansal M, Fernandez H, Perrotin F. Maternal outcome after conservative treatment of placenta accreta. Obstet Gynecol. 2010 Mar; 115: 526-34.

17. Read, John A, Cotton, David B, Miller Frank C. Placenta Accreta: Changing clinical aspects and outcome. Obstetrics \& Gynecology. Jul. 1980; Volume. 56.

18. Fitzpatrick KE, Sellers S, Spark P, Kurinczuk JJ, Brocklehurst P, Knight M. The management and outcomes of plaecntaaccreta, increta, and percreta in the UK: a population based descriptive study. BJOG, 2014; 121: 62-71. 